\title{
The aerobic capacity in patients with antisynthetase syndrome and dermatomyositis
}

\author{
Alexandre Moura dos Santos, Rafael Giovani Missé, Isabela Bruna Pires Borges and Samuel Katsuyuki Shinjo*
}

\begin{abstract}
Background: This study was aimed at evaluating the aerobic capacity of patients with antisynthetase syndrome (ASS) and dermatomyositis (DM) and analyzing possible relationships between aerobic capacity and disease status, cardiovascular diseases and their risk factors.

Methods: The study was a cross-sectional, single-center study that assessed the aerobic capacity of 22 women (13 with DM and 9 with ASS) who were matched by age and body mass index to 17 healthy women (control group). The aerobic capacity (oxygen uptake $\mathrm{VO}_{2}$ peak], anaerobic threshold, respiratory compensation point and time-toexhaustion) was evaluated using the cardiopulmonary treadmill test. Disease status was assessed using International Myositis Assessment \& Clinical Studies Group (IMACS) set scores.

Results: The patients had low IMACS parameters that showed low or absent disease activity. The distribution of cardiovascular diseases and their risk factors was similar between the patients and the control group $(P>0.05)$ at the time of the analysis. The patients with DM and the control group had similar aerobic capacity. However, the patients with ASS exhibited significantly reduced aerobic capacity (relative $\mathrm{VO}_{2}$ peak, anaerobic threshold, respiratory compensation point and time to exhaustion) when compared to the control group. In addition, patients with ASS had a lower anaerobic threshold compared to the DM group. There were no significant relationships between the aerobic capacity and disease status, cardiovascular diseases and their risk factors.

Conclusion: In contrast to DM patients and healthy individuals, patients with stable ASS have significantly impaired aerobic capacity, which is unlikely to be totally explained by traditional cardiovascular diseases, their risk factors and disease status. Further studies are needed to corroborate our data and to clarify the cause of this reduced aerobic capacity in ASS.
\end{abstract}

Keywords: Aerobic capacity, Antisynthetase syndrome, Dermatomyositis, Myositis

\section{Introduction}

Systemic autoimmune myopathies (SAMs) are a group of rare systemic autoimmune diseases that are clinically characterized by progressive skeletal muscle weakness [1]. Moreover, SAMs can present cutaneous lesions, such as heliotrope rash and Gottron's sign / papules, which occur in patients with dermatomyositis (DM) [1]. SAMs can also present pulmonary and articular involvements, fever, Raynaud's phenomenon, and "mechanic's

\footnotetext{
* Correspondence: samuel.shinjo@gmail.com

Division of Rheumatology, Faculdade de Medicina FMUSP, Universidade de Sao Paulo, Av. Dr. Arnaldo, 455, 30 andar, sala 3150 - Cerqueira César, Sao Paulo, SP CEP: 01246-903, Brazil
}

hand", which are also observed in patients with antisynthetase syndrome (ASS) [2, 3].

Patients with SAMs have a high prevalence of cardiovascular diseases (CVDs) and their risk factors [4-7]. Furthermore, sedentary behavior and physical inactivity may result in high rates of CVD risk factors and reduced aerobic capacity in the long term $[8,9]$.

Aerobic capacity is defined as the body's ability to capture, carry and use oxygen $[10,11]$. In clinical practice, the aerobic capacity is mainly used to evaluate the response of the cardiopulmonary, musculoskeletal and energy metabolism systems to the effort, enabling early detection of complications

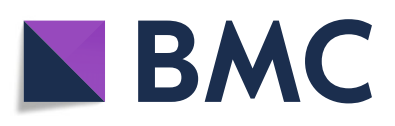

(c) The Author(s). 2019 Open Access This article is distributed under the terms of the Creative Commons Attribution 4.0 International License (http://creativecommons.org/licenses/by/4.0/), which permits unrestricted use, distribution, and reproduction in any medium, provided you give appropriate credit to the original author(s) and the source, provide a link to the Creative Commons license, and indicate if changes were made. The Creative Commons Public Domain Dedication waiver (http://creativecommons.org/publicdomain/zero/1.0/) applies to the data made available in this article, unless otherwise stated. 
in these systems; therefore, it is an important predictive tool of CVDs' outcomes and comorbidities [11].

Several researchers have shown the association between decreased aerobic capacity and increased risk of morbidity and mortality associated with CVDs [11-13]. Thus, increased aerobic capacity represents a significant improvement in functional capacity and quality of life, increased perception of self-reported physical health and a reduction in CVDs and their risk factors [14].

Although studies are scarce, aerobic capacity measurement has been the target of various studies in systemic autoimmune diseases [15-21]. For example, in rheumatoid arthritis, patients experience reduced aerobic capacity and lower levels of vigorous physical activity [15]. In juvenile rheumatoid arthritis, aerobic capacity reduction is related to disease activity [16], whereas in systemic lupus erythematosus, it is associated with greater fatigue and lower functional capacity $[17,18]$. In Sjögren's syndrome, patients with reduced aerobic capacity also have lower functional capacities, higher body pain levels and poorer quality of life [19].

Aerobic capacity reduction has also been described in a few studies of patients with DM and polymyositis $[8,9,20-22]$. However, some of these studies did not include details about disease status or drug therapy schemes (i.e., glucocorticoids) [9, 21, 22], which may promote muscle hypotrophy or atrophy and thus contribute to further aerobic capacity reduction [23]. In addition, to date, no study has analyzed aerobic capacity in patients with ASS separately.

Thus, the evaluation of aerobic capacity in patients with SAMs, and specifically in patients with ASS, could offer new perspectives on the use of cardiopulmonary tests to predict the risk of CVDs and, ultimately, the health of this population. Therefore, this study's objective was to assess aerobic capacity in patients with ASS and patients with $\mathrm{DM}$ and to analyze possible relationships between aerobic capacity and disease status, CVDs and their risk factors.

\section{Patients and methods}

This was a cross-sectional single-center study, in which 91 consecutive patients (60 with DM and 31 ASS) who attended regular follow-ups were initially selected from 2017 to 2018.

Patients with DM completed the European League Against Rheumatism / American College of Rheumatology (EULAR / ACR 2017) classification criteria [24], whereas those with ASS met the modified classification criteria of Connors et al. [2]. All patients had an serum autoantibody against aminoacyl-transfer ribonucleic acid synthetase and at least two out of the three aspects of the syndrome: muscle, joint and/or lung involvements, in addition to unexplained and persistent fever, Raynaud phenomenon and/or "mechanic's hands".
The present study is an extension of our previous study approved by the local ethics committee. In this context, male patients, patients with disease activity, patients with overlapping syndromes, patients who performed more than $150 \mathrm{~min}$ of moderate physical activity or $75 \mathrm{~min}$ of vigorous physical activity per week [25], patients with difficulty walking and patients with uncontrolled hypertension were excluded. In addition, patients who had used prednisone $>10$ $\mathrm{mg} /$ day within the last 3 months were excluded.

The patients' relatives or employees of our institution were selected as a control (CTR) group. Patients in the CTR group were age- and body mass index (BMI)-matched to patients with SAMs. In addition, we excluded individuals with any systemic autoimmune diseases, with uncontrolled systemic arterial hypertension, who used any medications that might compromise the treadmill cardiopulmonary test, who had individuals with walking difficulties or who performed more than $150 \mathrm{~min}$ of moderate physical activity or 75 min of vigorous physical activity per week [25].

The following data on eligible patients were collected from electronic medical records, using prestandardized and parameterized information:

A) Information referring to the initial diagnostic investigation:

- Demographics: Age at disease diagnosis

- Initial clinical manifestations: Constitutional symptoms, heliotrope rash, Gottron's sign / papules, "mechanic's hands", joint involvement (arthralgia or non-erosive arthritis), pulmonary involvement [defined as changes on high-resolution computer tomography images of the lung: incipient interstitial lung disease (ILD) and/or pulmonary fibrosis in both lung bases], Raynaud's phenomenon, dysphagia, muscle weakness (upper and lower limbs according to the Medical Research Council) [26].

- Laboratory parameters: Serum levels of creatine phosphokinase (reference value: 32-167 U/L), antisynthetase autoantibodies (anti-Jo-1, PL-7, PL12, OJ, and EJ). Serum samples stored at $-20^{\circ} \mathrm{C}$ were collected at the time of the initial disease activity investigation. The autoantibody identification was performed using a commercial kit (Myositis Profile 3, Euroimmun, Germany) according to the manufacturer's protocol. The evaluation of the results was based on the established method in a previous study [27]

B) Information referring to the patients when selected for the present study:

- Demographics: Current age, and BMI

- Current pulmonary involvement 
- Current disease status, which was assessed through IMACS: Manual Muscle Testing (MMT)8, Myositis Disease Activity Assessment Visual Analogue Scales (MYOACT), visual analog scale of the physician and the patient (VAS), Health Assessment Questionnaire (HAQ), and serum creatine phosphokinase (CPK) $[28,29]$.

- Treatment (i.e., glucocorticoid, immunosuppressive or immunobiological drugs)

- CVDs and its risk factors: acute myocardial infarction, stroke, congestive heart failure, type 2 diabetes mellitus, smoking, systemic arterial hypertension, dyslipidemia. We used as criterion for the diagnosis of dyslipidemia: plasma total cholesterol $>200 \mathrm{mg} / \mathrm{dL}$, LDL-cholesterol $>130$ $\mathrm{mg} / \mathrm{dL}$, triglycerides $>150 \mathrm{mg} / \mathrm{dL}, \mathrm{HDL}<50 \mathrm{mg} / \mathrm{dL}$ and/or drug treatment for evaluated dyslipidemia [30]. Hypertension was determined when patients received antihypertensive drugs or when systolic blood pressure was $\geq 140 \mathrm{mmHg}$ and/or diastolic pressure was $\geq 90 \mathrm{mmHg}$. The diagnosis of diabetes was based on the results of measurement of plasma glucose and/or drug treatment [31]. Smoking was considered active if it occurred at the time of analysis or within six months prior to the study

- Aerobic capacity: Patients and healthy individuals underwent a treadmill cardiopulmonary test (Centurion 200, Micromed), with ramp protocol (2.0 $\mathrm{mph} / 0 \%$ grade for the first 1 min stage, increasing to $2.5 \mathrm{mph} / 0 \%$ grade for the second stage, $3.0 \mathrm{mph}$ / 0\% grade for the third stage, $3.5 \mathrm{mph} / 0 \%$ grade for the fourth stage, and 2.5\% increments in grade each stage thereafter) performed until voluntary exhaustion. All subjects assessed were familiarized with the treadmill, rested for one hour before the actual test, and demonstrated the procedures to be performed during the test.

The test was performed in an air-conditioned laboratory $\left(20-22^{\circ} \mathrm{C}\right)$. Humidity and barometric pressure were continuously monitored during the evaluations. All cardiovascular and pulmonary responses were evaluated and controlled during the test, and the participants were connected to a computerized spiroergometer (MetaLyzer model 3B / breath-by-breath).

To define ventilatory thresholds, for the first threshold (i.e. ventilatory anaerobic threshold), we used the maximum point where energy production occurred exclusively through aerobic metabolism. For the second threshold (i.e. respiratory compensation point), we used the maximum limit that preceded ventilatory decompensation for acidosis. In addition to maximum oxygen consumption, we also considered $\mathrm{VO}_{2}$ peak in this case [10].
Statistical analysis. Data distribution was determined using the Shapiro-Wilk test, from which the normal data were expressed as mean \pm standard deviation. Data with asymmetric distribution were expressed as median (interquartile 25th - 75th). The categorical data were expressed by percentage (\%) and differences were analyzed using Fisher's test. The existence of differences in quantitative variables with normal distribution was analyzed through one-factor analysis (ANOVA) and Tukey's test was conducted to evaluate multiple comparisons. In the quantitative variables with asymmetric distribution, the Kruskal Wallis test and Dunn's test were conducted to evaluate multiple comparisons. The point biserial correlation $\left(\mathrm{r}_{\mathrm{pb}}\right)$ was used to evaluate the correlation between variables when one variable was continuous and the other dichotomous. In addition, $\mathrm{r}_{\mathrm{pb}}$ values was classified as low correlation $(<0.333)$, moderate correlation $(0.333-0.666)$ or strong correlation $(>0.666)$. The differences were considered statistically significant when at values of $P<0.05$. The analyses were performed with GraphPad Prism ${ }^{\circ}$ software version 6.01 for Windows (San Diego, California, USA).

\section{Results}

After applying the inclusion and exclusion criteria, 69 out of 91 patients were included in the present study. However, 47 patients did not agree to participate, so 22 patients (13 with DM and 9 with ASS) were included. Most patients from our center come from other cities or states. Moreover, most of them work. In contrast, the possible presence of symptoms, such as fatigue, pain and systemic manifestations were not causes exclusion criteria in the present study.

Seventeen CTR group individuals were also assessed (Fig. 1).

A) General characteristics of the patients at the time of disease diagnosis.

The mean age of patients with DM at the time of diagnosis was comparable to that of patients with ASS (40.2 years and 40.2 years, respectively; $P=0.999$ ) (Table 1 ).

The distribution of the initial clinical features such as constitutional symptoms, the presence of Raynaud's phenomenon, dysphagia and limb weakness was also similar between patients with DM and patients with ASS. However, joint and pulmonary involvements were statistically more frequent in patients with ASS than in those with DM.

Cutaneous involvement (heliotrope rash and Gottron's sign/papules) was present in the majority of patients with DM, whereas the presence of "mechanic's hands" was observed only in patients with ASS. 


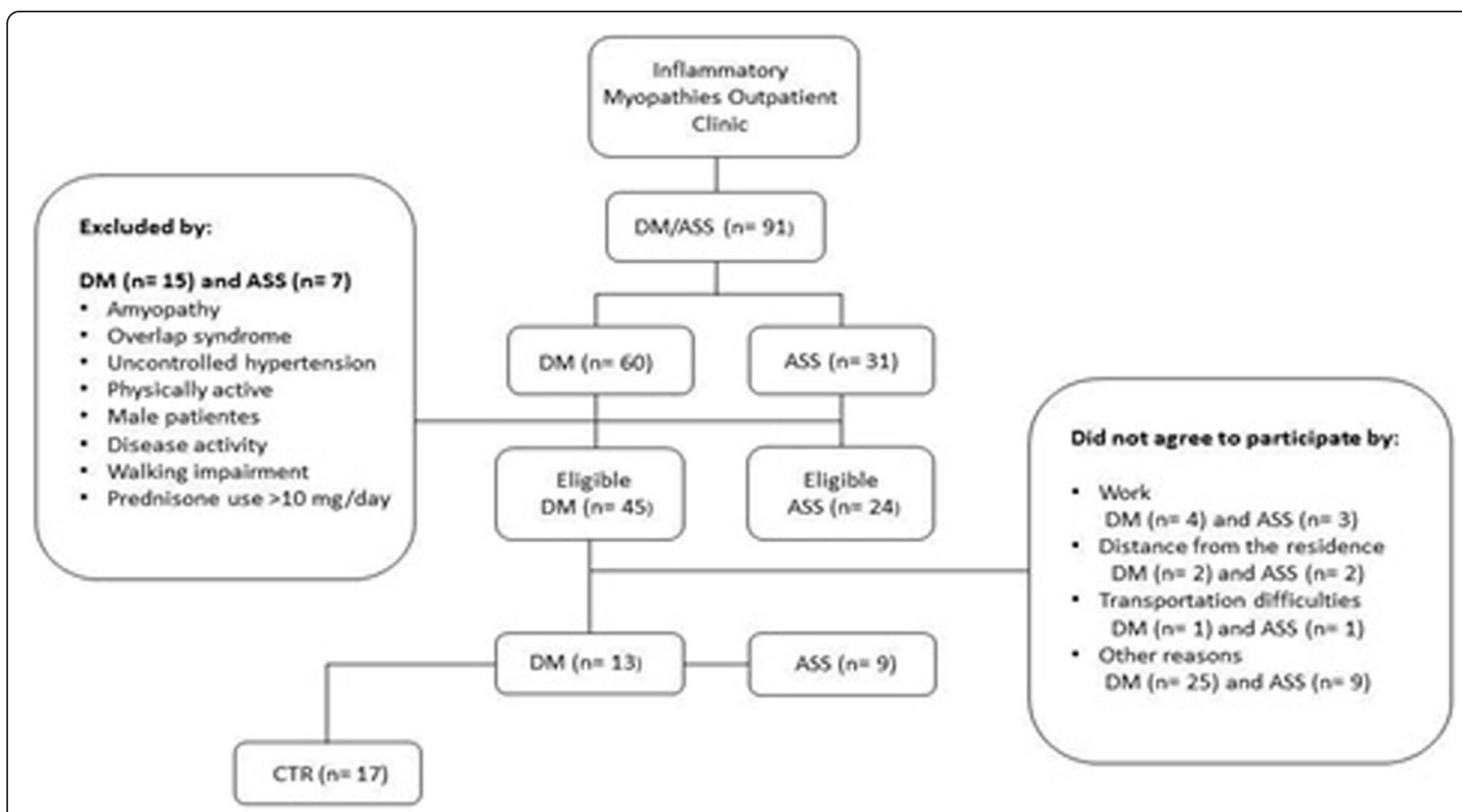

Fig. 1 Flowchart of patients with dermatomyositis and antisynthetase syndrome, and control group. ASS: antisynthetase syndrome; CTR: control group; DM: dermatomyositis.

The serum creatine phosphokinase (CPK) level at the time of diagnosis was similar for patients with DM and patients with ASS $(P=0.366)$.

In addition, all ASS patients had ASS autoantibodies: 8 patients had anti-Jo-1 and one patient had anti-PL-12 autoantibodies. Moreover, no DM patients had specificmyositis autoantibodies (i.e., anti-M-2 autoantibody) (Table 1).

B) Patients' general characteristics at the time of selection for the present study.

As expected, at the time of aerobic capacity analysis, current age and BMI values were comparable among patients in the DM, ASS and CTR groups (Table 2).

The distribution of lung involvement was also similar among the groups, as were IMACS parameters (HAQ, MMT-8, patient's VAS, physician's VAS, MYOACT, and $\mathrm{CPK}$ ) and prednisone levels (current use and median dose) (Table 2).

Regarding drug therapy, 12 patients with DM and 9 patients with ASS used one or more immunosuppressive or immunobiological agents. In addition, fewer than half of the patients in the DM and ASS groups used prednisone. The median dose was $0.0(0.0-7.5) \mathrm{mg} /$ day and 0.0 $(0.0-10.0) \mathrm{mg} /$ day, respectively (Table 2 ).

In relation to CVDs and their risk factors, half of the patients in the DM and ASS groups had systemic arterial hypertension and dyslipidemia, which were also found in the CTR group. Approximately one-fifth of patients had type 2 diabetes mellitus, whereas the CTR group had no cases. Moreover, no groups contained cases of acute myocardial infarction, stroke, congestive heart failure or current smoking habit (Table 3).

The patients with DM and the CTR group had similar aerobic capacity parameters. However, patients with ASS had significantly reduced relative $\mathrm{VO}_{2}$ peaks, anaerobic thresholds, respiratory compensation points and exhaustion times when compared to the CTR group. In addition, patients with ASS had lower anaerobic thresholds when compared to DM patients (Table 4, Figs. 2 and 3).

There were no relationships between aerobic capacity parameters and disease status, patients' drug treatment scheme, CVDs and their risk factors in patients with DM and patients with ASS.

\section{Discussion}

In the present study, a significant reduction in aerobic capacity was observed in stable patients with ASS when compared to stable patients with DM and healthy females. The impairment observed in the ASS group was apparently independent of the traditional factors that interfere with aerobic capacity parameters, such as CVDs and their risk factors, disease status and patients' drug treatment schemes. 
Table 1 General features of patients with dermatomyositis and antisynthetase syndrome at disease onset

\begin{tabular}{|c|c|c|c|}
\hline & $\begin{array}{l}\text { DM } \\
(n=13)\end{array}$ & $\begin{array}{l}\text { ASS } \\
(n=9) \\
\end{array}$ & $P$ \\
\hline Age at disease diagnosis (years) & $40.2 \pm 11.5$ & $40.2 \pm 10.2$ & 0.999 \\
\hline \multicolumn{4}{|l|}{ Clinical manifestations (\%) } \\
\hline Constitutional symptoms & $8(61.5)$ & $8(88.9)$ & 0.333 \\
\hline \multicolumn{4}{|l|}{ Skin involvement } \\
\hline Heliotrope rash & $12(92.3)$ & 0 & - \\
\hline Gottron's sign & $12(92.3)$ & 0 & - \\
\hline Gottron's papule & $12(92.3)$ & 0 & - \\
\hline "Mechanic's hands" & 0 & $6(66.7)$ & - \\
\hline Joint involvement & $2(15.4)$ & $8(88.9)$ & 0.001 \\
\hline Pulmonary involvement & $4(30.8)$ & $9(100.0)$ & 0.001 \\
\hline Raynaud's phenomenon & $6(46.2)$ & $8(88.9)$ & 0.165 \\
\hline Dysphagia & $8(61.5)$ & $3(33.3)$ & 0.193 \\
\hline \multicolumn{4}{|l|}{ Muscle involvement (\%) } \\
\hline \multicolumn{4}{|l|}{ Upper limbs (muscle strength) } \\
\hline Degree ॥ & 0 & 0 & \multirow[t]{5}{*}{0.689} \\
\hline Degree II & 0 & 0 & \\
\hline Degree III & $2(15.8)$ & $2(22.2)$ & \\
\hline Degree IV & $11(84.2)$ & $6(66.7)$ & \\
\hline Degree V & 0 & $1(11.1)$ & \\
\hline \multicolumn{4}{|l|}{ Lower limbs (muscle strength) } \\
\hline Degree ॥ & 0 & 0 & \multirow[t]{5}{*}{0.973} \\
\hline Degree II & 0 & 0 & \\
\hline Degree III & $3(23.1)$ & $2(22.2)$ & \\
\hline Degree IV & $9(69.2)$ & $6(66.7)$ & \\
\hline Degree V & $1(7.7)$ & $1(11.1)$ & \\
\hline \multicolumn{4}{|l|}{ Laboratory parameters } \\
\hline Creatine phosphokinase $(\mathrm{U} / \mathrm{L})$ & $2300(999-6326)$ & $967(292-6654)$ & 0.366 \\
\hline \multicolumn{4}{|l|}{ Antisynthetase autoantibodies (\%) } \\
\hline Anti- Jo-1 & 0 & $8(88.9)$ & - \\
\hline Anti-PL-12 & 0 & $1(11.1)$ & - \\
\hline
\end{tabular}

ASS antisynthetase syndrome, DM dermatomyositis

The present study provided detailed descriptions of disease status using IMACS scores and patient drug therapy, allowing for better clinical, laboratory and therapeutic characterization of the patients at the time of analysis of the aerobic capacity.

Our patients showed stable disease activity, and fewer than half of patients used prednisone. Those who did used a low daily dose. Therefore, the patients had relatively stable disease. In other words, they had no disease activity and were clinically stable.

Another relevant aspect was the use of the cardiopulmonary test and treadmill to evaluate aerobic capacity. This is considered a gold standard for this evaluation [32]. Berntsen et al. [22], for example, used the 6-min walk test. This test is submaximal, but it does not allow for the precise determination of mechanisms that limit physical exercise, metabolic thresholds, $\mathrm{VO}_{2}$ peaks, ischemia and cardiopulmonary diseases [32, 33].

The third important aspect of the present study is that patients were gender-, age- and BMI-matched to the CTR group. Furthermore, exclusion criteria were applied to avoid effects arising from confounding factors, which could compromise aerobic capacity analysis. In addition, we described the status of the disease at two moments, at diagnosis and at the time of study analysis.

Finally, to our knowledge, this is the first time aerobic capacity has been assessed separately in patients with ASS. 
Table 2 Current anthropometric feature, pulmonary involvement, disease status and drug treatment of patients with dermatomyositis and antisynthetase syndrome, and control group (at the time of analysis)

\begin{tabular}{|c|c|c|c|c|c|c|}
\hline & \multirow{2}{*}{$\begin{array}{l}\text { DM } \\
(n=13)\end{array}$} & \multirow{2}{*}{$\begin{array}{l}\text { ASS } \\
(n=9)\end{array}$} & \multirow{2}{*}{$\begin{array}{l}\text { CTR } \\
n=17\end{array}$} & \multicolumn{3}{|l|}{$P$} \\
\hline & & & & DM vs. CTR & ASS vs. CTR & DM vs. ASS \\
\hline Current age (years) & $48.1 \pm 9.4$ & $46.9 \pm 10.2$ & $47.76 \pm 4.44$ & 0.993 & 0.960 & 0.935 \\
\hline Time of disease (years) & $7.9 \pm 4.5$ & $6.7 \pm 3.9$ & - & - & - & 0.785 \\
\hline Body mass index $\left(\mathrm{kg} / \mathrm{m}^{2}\right)$ & $29.2(23.9-35.2)$ & $32.2(31.8-35.6)$ & $28.5(25.5-30.2)$ & $>0.999$ & 0.056 & 0.189 \\
\hline Pulmonary involvement (\%) & $1(7.7)$ & $3(33.3)$ & - & - & - & 0.167 \\
\hline Disease status ${ }^{\mathrm{b}}$ & & & - & - & - & \\
\hline HAQ (0.00-3.00) & $0.06(0.00-0.34)$ & $0.50(0.00-0.75)$ & - & - & - & 0.451 \\
\hline MMT-8 (0-80) & $80(80-80)$ & $80(80-80)$ & - & - & - & $>0.999$ \\
\hline Patients' VAS (0-10) & $0.0(0.0-1.0)$ & $0.0(0.0-0.0)$ & - & - & - & 0.408 \\
\hline Physician' VAS (0-10) & $0.0(0.0-0.0)$ & $0.0(0.0-0.0)$ & - & - & - & 0.544 \\
\hline MYOACT (0-60) & $0.0(0.0-0.0)$ & $0.0(0.0-0.0)$ & - & - & - & 0.746 \\
\hline Creatine phosphokinase $(U / L)$ & $97(70-149)$ & $141(85-204)$ & - & - & - & 0.180 \\
\hline Treatment & & & - & - & - & \\
\hline Prednisone & & & - & - & - & \\
\hline Current use (\%) & $5(29.4)$ & $4(44.4)$ & - & - & - & $>0.999$ \\
\hline Dose (mg/day) & $0.0(0.0-7.5)$ & $0.0(0.0-10.0)$ & - & - & - & 0.337 \\
\hline IS or immunobiological (\%) & & & - & - & - & \\
\hline Current use of one or more & $12(92.3)$ & $9(100.0)$ & - & - & - & $>0.999$ \\
\hline Azathioprine & $5(29.4)$ & $5(55.6)$ & - & - & - & 0.666 \\
\hline Methotrexate & $6(46.2)$ & $3(33.3)$ & - & - & - & 0.674 \\
\hline Others $^{a}$ & $2(15.4)$ & $5(55.6)$ & - & - & - & 0.290 \\
\hline Rituximab & 0 & $1(11.1)$ & - & - & - & - \\
\hline
\end{tabular}

ASS antisynthetase syndrome, DM dermatomyositis, HAQ Health Assessment Questionnaire; IS: immunosuppressive, MMT Manual Muscle Testing, MYOACT Myositis Disease Activity Assessment, VAS Visual Analogue Scale

${ }^{a}$ Others: mycophenolate mofetil and leflunomide

${ }^{\mathrm{b}}$ Results expressed as mean and standard deviation and median and interquartile range (25th-75th)

In the initial phase of the disease, as expected, the patients with ASS experienced not only myositis, but also joint and pulmonary involvement, which are characteristic of this disease. However, at the time of this study's analysis, patients with DM and patients with ASS had similar clinical, laboratory and therapeutic characteristics, including pulmonary involvement. Despite these comparable data, patients with ASS experienced a significant impairment in aerobic capacity.

The reduction of aerobic capacity in healthy subjects and in patients with systemic autoimmune diseases could contribute to an increase in CVDs and their risk factors, as well as a decrease in functional capacity. As a result, such patients' sedentary time increases, making

Table 3 Current presence of cardiovascular disease and theirs risk factors in patients and control group

\begin{tabular}{|c|c|c|c|c|c|c|}
\hline & \multirow{2}{*}{$\begin{array}{l}\text { DM } \\
(n= \\
13)\end{array}$} & \multirow{2}{*}{$\begin{array}{l}\text { ASS } \\
(n=9)\end{array}$} & \multirow{2}{*}{$\begin{array}{l}\text { CTR } \\
(n=17)\end{array}$} & \multicolumn{3}{|l|}{$P$} \\
\hline & & & & DM vs. CTR & ASS vs. CTR & DM vs. ASS \\
\hline Systemic arterial hypertension (\%) & $7(53.9)$ & $5(55.6)$ & $4(23.5)$ & 0.132 & 0.194 & $>0.999$ \\
\hline Dyslipidemia & $7(53.9)$ & $4(44.4)$ & $11(64.7)$ & 0.711 & 0.419 & $>0.999$ \\
\hline Diabetes mellitus & $2(15.4)$ & $2(22.2)$ & 0 & - & - & \\
\hline Acute myocardial infarction & 0 & 0 & 0 & - & - & - \\
\hline Stroke & 0 & 0 & 0 & - & - & - \\
\hline Congestive heart failure & 0 & 0 & 0 & - & - & - \\
\hline Smoking habit & 0 & 0 & 0 & - & - & - \\
\hline
\end{tabular}

ASS antisynthetase syndrome, CTR control group, DM dermatomyositis 
Table 4 Parameters of aerobic capacity of the control group and of patients with antisynthetase syndrome and dermatomyositis

\begin{tabular}{lllllll}
\hline & $\begin{array}{l}\text { DM } \\
(n=13)\end{array}$ & $\begin{array}{l}\text { ASS } \\
(n=9)\end{array}$ & $\begin{array}{l}\text { CTR } \\
(n=17)\end{array}$ & DM vs. CTR & ASS vs. CTR & DM vs. ASS \\
\cline { 5 - 7 } & $19.4 \pm 3.9$ & $16.5 \pm 3.1$ & $22.4 \pm 4.5$ & 0.121 & 0.003 & 0.239 \\
$\mathrm{VO}_{2}$ peak (mL/kg/min) & $1.4(1.1-1.7)$ & $1.4(1.2-1.6)$ & $1.7(1.3-1.8)$ & 0.212 & 0.367 & $>0.999$ \\
$\mathrm{VO}_{2}$ peak (L/min) & $5.1 \pm 1.5$ & $3.7 \pm 0.9$ & $5.2 \pm 1.2$ & 0.965 & 0.016 & 0.037 \\
Anaerobic threshold (min) & $9.6 \pm 1.7$ & $7.6 \pm 2.2$ & $10.6 \pm 2.4$ & 0.383 & 0.003 & 0.087 \\
Respiratory compensation point (min) & $11.1 \pm 2.0$ & $9.0 \pm 2.1$ & $12.7 \pm 2.2$ & 0.134 & $<0.001$ & 0.061 \\
Time-to-exhaustion (min) & & &
\end{tabular}

ASS antisynthetase syndrome, CTR control group, DM dermatomyositis, $\mathrm{VO}_{2}$ volume of oxygen

this process a vicious circle that can result in a chronic increase in morbidity and mortality in patients [34-36].

Lower aerobic capacity translates into greater difficulty to perform physical activities, whether daily, at work or in physical exercises,. This leads us to believe that this reduction could be related to the high levels of sedentary behavior in this population, which contributes to the reduction of their overall health, further intensifies the onset of comorbidities and correlates with poorer health in patients with ASS in the long term $[35,36]$.

Newall et al. [37] observed that patients with ANCAassociated vasculitis present a moderate inverse correlation between the variables used to assessed lung function and aerobic capacity $(r h o=0.50-0.74)$. However, the patients analyzed in the present study, including patients with ASS did not present major pulmonary compromises at the time of the cardiopulmonary test despite having considerably reduced aerobic capacities.

At the time of analysis, the groups did not present significant differences, in traditional CVD risk factors when compared to each other. This leads us to hypothesize that the marked reduction of the aerobic capacity in patients with ASS is independent of CVD risk factors, which were similar in both patient groups and the CTR group.
This demonstrates that the difference in aerobic capacity found in patients with ASS is not caused by comorbidities related to CVD risk factors.

We found a small difference in the BMI of the ASS group, but this not statistically significant when compared to the other groups. However, given the possible interference of this factor in $\mathrm{VO}_{2}$ peak measurement, we must take into consideration the low specificity of BMI when used to assess body composition. For example, patients with lower BMIs may have less lean mass (muscle), have lower weights and therefore be more critical and exhibit with lower functional capacity and lower test responses, or vice versa [38]. However, we could have performed a more accurate body composition analysis to draw a more adequate parallel between composition and aerobic capacity.

In addition, muscle involvement in patients with SAMs, especially patients with ASS, and its direct relationship with metabolic processes, may further reduce aerobic capacity to the level of a possible independent risk factor for CVDs in this population, for which CVDs have a high mortality rate $[4-7,39]$.

The literature contains positive and consolidated results regarding the contribution of physical training to the improvement and maintenance of aerobic capacity in patients with systemic autoimmune diseases [8, 20, 40-44]. In this

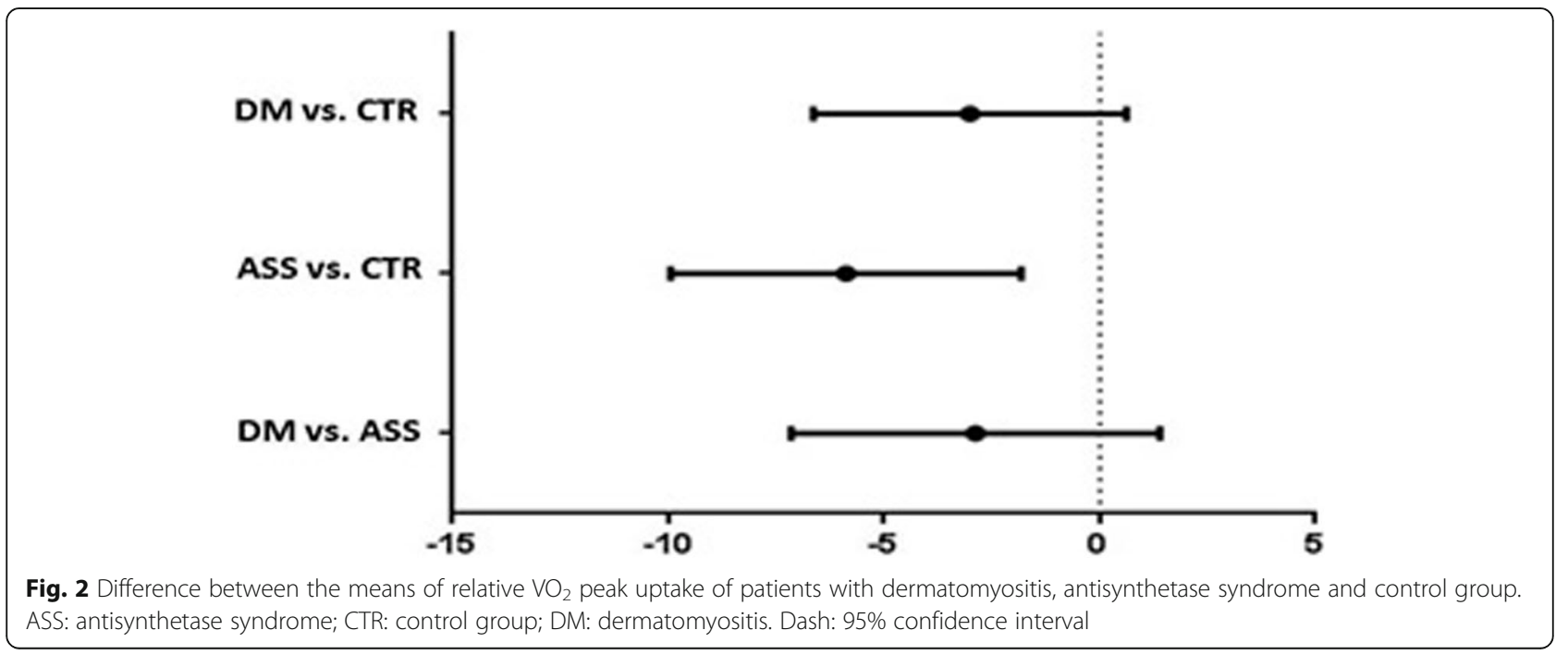




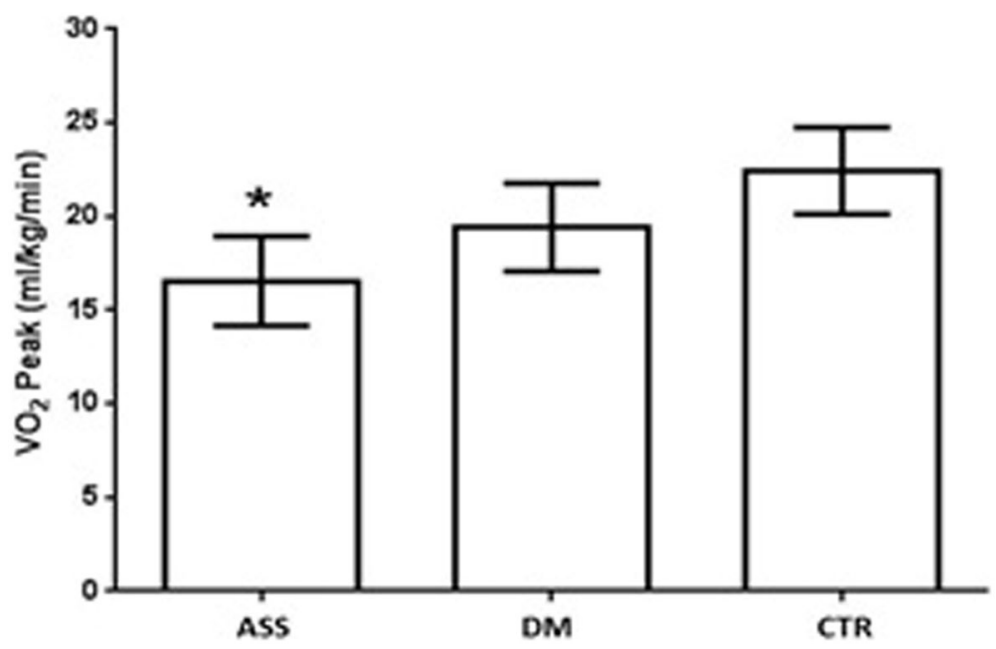

Fig. 3 Relative peak of $\mathrm{VO}_{2}$ from patients with dermatomyositis and antisyintetase syndrome compared to the control group. ASS: antisynthetase syndrome; CTR: control group; DM: dermatomyositis; $\mathrm{VO}_{2}$ : volume of oxygen. Dash: $95 \%$ confidence interval; ${ }^{*} P<0.05$

context, it would be interesting to carry out future studies to evaluate physical exercise programs aimed at increasing aerobic capacity in patients with ASS, and focused mainly on reducing the risks of morbidity and mortality in these patients.

The present study had some limitations. First, we could not emphasize the nonperformance of physical activity level measurement tests directly, for example, an accelerometer. This factor could have interfered with the analysis. Second, we performed a cross-sectional analysis, so a longitudinal analysis is necessary to establish the possible relationships between aerobic capacity and SAMs. Third, we had a small sample; therefore, further studies with larger samples are necessary to corroborate our data and possible correlations.

\section{Conclusions}

Patients with stable ASS demonstrated impaired of aerobic capacity. Therefore, strategies that can improve the aerobic capacity of this population can be used to promote better quality of life.

\section{Abbreviations \\ ACR: American College of Rheumatology; ASS: Antisynthetase syndrome; BMI: Body mass index; CPK: Creatine phosphokinase; CTR: Control group; CVDs: Cardiovascular diseases; DM: Dermatomyositis; EULAR: European League Against Rheumatism; HAQ: Health Assessment Questionnaire; ILD: Interstitial lung disease; IMACS: International Myositis Assessment \& Clinical Studies Group; MMT: Manual Muscle Testing; MYOACT: Myositis Disease Activity Assessment Visual Analogue Scales; SAM: Systemic autoimmune myopathies; VAS: Visual analog scale; $\mathrm{VO}_{2}$ : Oxygen uptake}

\section{Acknowledgments}

Diego Sales de Oliveira e Jean Marcos de Souza for initial data collections. All members from Laboratório de Avaliação e Condicionamento da Reumatologia (LACRE) - HCFMUSP - SP.

\section{Authors' contributions}

All authors contributed equally to write and review the manuscript. All authors read and approved the final manuscript.

\section{Funding}

This work was funded by: Fundação de Amparo à Pesquisa do Estado de São Paulo (FAPESP) to: AMS (\#2018/08735-3), RGM (\#2016/23574-0), IBPB (\#2016/20371-1) and SKS (\#2017/13109-1); Faculdade de Medicina da Universidade de São Paulo / SP to SKS.

Availability of data and materials

Please contact author for data requested.

\section{Ethics approval and consent to participate}

This study was approved by the local Ethics Committee (HCFMUSP, CAAE 61474416.5.0000.0068) and all participants signed the informed consent form.

\section{Consent for publication}

Not applicable.

\section{Competing interests}

The authors declare that they have no competing interests.

Received: 30 May 2019 Accepted: 23 December 2019

Published online: 31 December 2019

\section{References}

1. Dalakas MC. Polymyositis, dermatomyositis and inclusion-body myositis. N Engl J Med. 1991;325:1487-98.

2. Connors GR, Christopher-Stine L, Oddis CV, Danoff SK. Interstitial lung disease associated with the idiopathic inflammatory myopathies: what progress has been made in the past 35 years? Chest. 2010:138:1464-74.

3. Shinjo SK, Levy-Neto M. Anti-Jo-1 antisynthetase syndrome. Rev Bras Reumatol. 2010;50:492-500.

4. Araujo PAO, Silva MG, Borba EF, Shinjo SK. High prevalence of metabolic syndrome in antisynthetase syndrome. Clin Exp Rheumatol. 2018;36:241-7.

5. Silva MG, Borba EF, Mello SB, Shinjo SK. Serum adipocytokine profile and metabolic syndrome in young adult female dermatomyositis patients. Clinics (Sao Paulo). 2016;71:709-14

6. de Souza FH, Shinjo SK. The high prevalence of metabolic syndrome in polymyositis. Clin Exp Rheumatol. 2014;32:82-7.

7. de Moraes MT, de Souza FH, de Barros TB, Shinjo SK. Analysis of metabolic syndrome in adult dermatomyositis with a focus on cardiovascular disease. Arthritis Care Res (Hoboken). 2013;65:793-9. 
8. Alemo Munters L, Dastmalchi M, Katz A, Esbjörnsson M, Loell I, Hanna B, et al. Improved exercise performance and increased aerobic capacity after endurance training of patients with stable polymyositis and dermatomyositis. Arthritis Res Ther. 2013;15:83.

9. Wiesinger GF, Quittan M, Aringer M, Seeber A, Volc-Platzer B, Smolen J, et al. Improvement of physical fitness and muscle strength in polymyositis / dermatomyositis patients by a training programme. Br J Rheumatol. 1998; 37:196-200.

10. Wasserman K, Whipp BJ, Koyl SN, Beaver WL. Anaerobic threshold and respiratory gas exchange during exercise. J Appl Physiol. 1973:35:236-43.

11. Booth FW, Roberts CK, Laye MJ. Lack of exercise is a major cause of chronic diseases. Compr Physiol. 2012;2:1143-211.

12. Laukkanen JA, Rauramaa R, Kurl S. Exercise workload, coronary risk evaluation and the risk of cardiovascular and all-cause death in middle-aged men. Eur J Cardiovasc Prev Rehabil. 2008;15:285-92.

13. Ladenvall P, Persson CU, Mandalenakis Z, Wilhelmsen L, Grimby G, Svardsudd $K$, et al. Low aerobic capacity in middle-aged men associated with increased mortality rates during 45 years of follow-up. Eur J Prev Cardiol. 2016;23:1557-64

14. Chen $\mathrm{CH}$, Chen YJ, Tu HP, Huang MH, Jhong JH, Lin KL. Benefits of exercise training and the correlation between aerobic capacity and functional outcomes and quality of life in elderly patients with coronary artery disease. Kaohsiung J Med Sci. 2014;30:521-30.

15. Munsterman T, Takken T, Wittink H. Are persons with rheumatoid arthritis deconditioned? A review of physical activity and aerobic capacity. BMC Musculoskelet Disord. 2012;13:202.

16. van Pelt PA, Takken T, van Brussel M, de Witte I, Kruize AA, Wulffraat NM. Aerobic capacity and disease activity in children, adolescents and young adults with juvenile idiopathic arthritis (JIA). Pediatr Rheumatol J. 2012;10:27

17. Robb-Nicholson LC, Daltroy L, Eaton H, Gall V, Wright E, Hartley LH, et al. Effects of aerobic conditioning in lupus fatigue: a pilot study. $\mathrm{Br} J$ Rheumatol. 1989;28:500-5.

18. Tench C, Bentley D, Vleck V, McCurdie I, White P, D'Cruz D. Aerobic fitness, fatigue, and physical disability in systemic lupus erythematosus. J Rheumatol. 2002;29:474-81.

19. Dassouki T, Benatti FB, Pinto AJ, Roschel H, Lima FR, Augusto K, et al. Objectively measured physical activity and its influence on physical capacity and clinical parameters in patients with primary Sjogren's syndrome. Lupus. 2017;26:690-7.

20. Alemo Munters L, Dastmalchi M, Andgren V, Emilson C, Bergegård J, Regardt $M$, et al. Improvement in health and possible reduction in disease activity using endurance exercise in patients with established polymyositis and dermatomyositis: a multicenter randomized controlled trial with a 1-year open extension followup. Arthritis Care Res (Hoboken). 2013;65:1959-68.

21. Wiesinger GF, Quittan M, Nuhr M, Volc-Platzer B, Ebenbichler G, Zehetgruber $M$, et al. Aerobic capacity in adult dermatomyositis/polymyositis patients and healthy controls. Arch Phys Med Rehabil. 2000;81:1-5.

22. Berntsen KS, Tollisen A, Schwartz T, Kirkhus E, Aalokken TM, Lund MB, et al. Submaximal exercise capacity in juvenile dermatomyositis after longterm disease: the contribution of muscle, lung, and heart involvement. J Rheumatol. 2017:44:827-34.

23. Mastaglia FL. Adverse effects of drugs on muscle. Drugs. 1983:24:304-21.

24. Lundberg IE, Tjarnlund A, Bottai M, Werth VP, Pilkington C, de Visser M, et al. 2017 European league against rheumatism/American College of Rheumatology Classification Criteria for adult and juvenile idiopathic inflammatory myopathies and their major subgroups. Arthritis Rheumatol. 2017;69:2271-82.

25. Global recommendations on physical activity for health. Geneva: World Health Organization, 2010.

26. Marsden C. Aids to the examination of the peripheral nervous system. The Editorial Committee for the Guarantors of Brain. J Neurol Neurosurg Psychiatry. 1987;50:124

27. Cruellas MG, Viana Vdos S, Levy-Neto M, Souza FH, Shinjo SK. Myositisspecific and myositis-associated autoantibody profiles and their clinical associations in a large series of patients with polymyositis and dermatomyositis. Clinics (Sao Paulo). 2013:68:909-14.

28. Rider LG, Werth VP, Huber AM, Alexanderson H, Rao AP, Ruperto N, et al. Measures for adult and juvenile dermatomyositis, polymyositis, and inclusion body myositis. Arthritis Care Res (Hoboken). 2011;63:118-57.

29. Sultan SM. Clinical assessment in adult onset idiopathic inflammatory myopathy. Curr Opin Rheumatol. 2019;16:668-72.
30. De Backer G, Ambrosioni E, Borch-Johnsen K, Brotons C, Cifkova R, Dallongeville J, et al. European guidelines on cardiovascular disease prevention in clinical practice: third joint task force of European and other societies on cardiovascular disease prevention in clinical practice (constituted by representatives of eight societies and by invited experts). Eur J Cardiovasc Prev Rehabil. 2003;10:1-10.

31. American Diabetes Association. Diagnosis and classification of diabetes mellitus. Diabetes Care. 2011;34:62-9.

32. Weisman IM, Zeballos RJ. Clinical exercise testing. Clin Chest Med. 2001;22: 679-701.

33. Fletcher GF, Ades PA, Kligfield P, Arena R, Balady GJ, Bittner VA, et al. Exercise standards for testing and training: a scientific statement from the American Heart Association. Circulation. 2013;128:873-934.

34. Kodama S, Saito K, Tanaka S, Maki M, Yachi Y, Asumi M, et al. Cardiorespiratory fitness as a quantitative predictor of all-cause mortality and cardiovascular events in healthy men and women: a meta-analysis. JAMA. 2009;301:2024-35.

35. Sultan SM, loannou Y, Moss K, Isenberg DA. Outcome in patients with idiopathic inflammatory myositis: morbidity and mortality. Rheumatology (Oxford). 2002;41:22-6.

36. Sokka T, Hakkinen A. Poor physical fitness and performance as predictors of mortality in normal populations and patients with rheumatic and other diseases. Clin Exp Rheumatol. 2008;26:14-20

37. Newall C, Schinke S, Savage CO, Hill S, Harper L. Impairment of lung function, health status and functional capacity in patients with ANCAassociated vasculitis. Rheumatology (Oxford). 2005;44:623-8.

38. Bosy-Westphal A, Braun W, Geisler C, Norman K, Muller MJ. Body composition and cardiometabolic health: the need for novel concepts. Eur J Clin Nutr. 2018;72:638-44.

39. Gupta S, Rohatgi A, Ayers CR, Willis BL, Haskell WL, Khera A, et al. Cardiorespiratory fitness and classification of risk of cardiovascular disease mortality. Circulation. 2011;123:1377-83.

40. Stavropoulos-Kalinoglou A, Metsios GS, Veldhuijzen van Zanten JJ, Nightingale $P$, Kitas GD, Koutedakis Y. Individualised aerobic and resistance exercise training improves cardiorespiratory fitness and reduces cardiovascular risk in patients with rheumatoid arthritis. Ann Rheum Dis. 2013;72:1819-25.

41. Carvalho MR, Sato El, Tebexreni AS, Heidecher RT, Schenkman S, Neto TL. Effects of supervised cardiovascular training program on exercise tolerance, aerobic capacity, and quality of life in patients with systemic lupus erythematosus. Arthritis Rheum. 2005;53:838-44.

42. Bostrom C, Elfving B, Dupre B, Opava CH, Lundberg IE, Jansson E. Effects of a one-year physical activity programme for women with systemic lupus erythematosus - a randomized controlled study. Lupus. 2016;25:602-16.

43. Santos AM, Oliveira DS, Misse RG, Perin LA, Souza J, Lima FR, et al. Impact of an exercise training program in a patient with relapsing polychondritis: a case report. Open J Rheumatol Autoimmun Dis. 2018;08:93.

44. De Souza JM, de Oliveira DS, Perin LA, Misse RG, Dos Santos AM, Gualano B, et al. Feasibility, safety and efficacy of exercise training in immune-mediated necrotising myopathies: a quasi-experimental prospective study. Clin Exp Rheumatol. 2018:37:235-41.

\section{Publisher's Note}

Springer Nature remains neutral with regard to jurisdictional claims in published maps and institutional affiliations.

Ready to submit your research? Choose BMC and benefit from:

- fast, convenient online submission

- thorough peer review by experienced researchers in your field

- rapid publication on acceptance

- support for research data, including large and complex data types

- gold Open Access which fosters wider collaboration and increased citations

- maximum visibility for your research: over $100 \mathrm{M}$ website views per year

At $\mathrm{BMC}$, research is always in progress.

Learn more biomedcentral.com/submissions 